\title{
Motives for Decreasing the Curing Time of HTPB-AP Composite Propellants
}

\author{
Nagmeldin. M. Elamin*, Ahmed M. Bashir ${ }^{\dagger}$ \\ *Defense Industries System, Advanced Industries Group, Sudan, Email: nagmamin59@gmail.com \\ ${ }^{\dagger}$ Defense Industries System, Sabighat Industrial Complex, Sudan, Email: a7medmahjoub@gmail.com
}

\begin{abstract}
One of the standard conditions for solidifying composite propellants consist of hydroxyl terminated poly-butadiene as a binder and ammonium perchlorate as oxidizer, is the curing process for certain time in a certain temperature. On this paper, the motives and reasons for the decreasing of this curing time were studied and discussed. The study and discussion include the productivity, cost, delivery, manpower, and maintenance points of view. By experiments and questionnaire work, it was seen that, all the previous points of view were affected positively. Generally, the productivity of the propellant was increased by $100 \%$, the cost of curing process was decreased by $25 \%$ of the previous cost, the man power needed for the process of waiting and recording the readings was decreased by $50 \%$, customer delivery process was fasted by $50 \%$ of the previous delivery time, and finally the maintenance processes due to equipment depreciation were improved by $50 \%$ from the previous. From the whole point of view, it was seen that, the decreasing of the curing time is very useful for the production of the propellant. Finally, it is observed that the decreasing of the curing time to the half time brought the same properties of the standard curing time, and then it is concluded that the deceasing of the curing time can be applied safely and usefully in the casting production line.
\end{abstract}

Key words-Composite propellant, Curing time, Curing temperature, Burning rate

\section{INTRODUCTION}

Hydroxyl terminated poly butadiene (HTPB) is a liquid rubber with poly-butadiene as the main chain and hydroxyl as the terminal, it is a most common type of polyol used to produce polyurethane (PU). This pre-polymer has fine physical properties such as low glass transition temperature (Tg) a low viscosity. Not only had that HTPB reacts with isocyanates to form polyurethane elastomer, but also had good mechanical performance [1]. Although ammonium perchlorate (AP) composite propellant has been three dimensional (3D) printed at solids loadings that are comparable to traditional formulations with vibration assisted printing (VAP), traditional propellant binders such as hydroxyl terminated polybutadiene (HTPB) are poorly suited for 3D printing large or complex structures because propellant made with HTPB deforms easily under its own weight and isocyanates do not crosslink HTPB fast enough to facilitate rapid polymerization after deposition [2]. The ingredients consisted of a polybutadiene urethane acrylate and hexanediol diacrylate (HDDA) polymer binder, which could be mixed in various ratios to control properties such as adhesion to particle surfaces and viscosity, as well as bis-acyl phosphine oxide (BAPO) which is a well-known photo initiator for deep curing in the coatings industry [2].

Traditional composite propellants are cured by treatment of hydroxyl-terminated prepolymers with polyfunctional aliphatic isocyanates. For development of smokeless composite propellants containing nitramines and/or ammonium dinitramide (ADN), energetic binder systems using glycol azide polymer (GAP) are of particular interest. Poly functional alkynes are potential isocyanate-free curing agents for GAP through thermal azide-alkyne cyclo addition and subsequent formation of triazole cross linkages. Propargyl succinate or closely related aliphatic derivatives have previously been reported for such isocyanate-free curing of GAP [3]. The influence of the process parameters such as premix temperature, cure time and temperature, sequence of solid ingredients addition, final mixing time and the nature of propellant ingredients such as curative type, hydroxyl content of HTPB binder, concentration of chain modifiers and their relative ratio have significant roles in deciding the fracture toughness of the propellant specimen. The stress-strain behaviour is one of the best methods of representing the specimen failure. It is proven that the fracture toughness is one of the finest tools in deciding the capability of CSP to withstand severe stresses from various conditions [4]. Uniaxial tensile tests of different composite solid rocket propellant compositions, based on (HTPB), have shown that mechanical properties extensively change after curing, up to $100 \%$ of their initial values, during the first few months. Then, they stabilize and start to return slowly in the reverse direction. Careful measurements of these features are necessary in order to control production quality of the propellant and for comparison of different propellant compositions or batches. Furthermore, time distributions of the mechanical properties in the initial period after production and short-time aging should not be neglected, because they strongly affect propellant grain structural analysis and correct estimation of rocket motor reliability [5].

Solid rocket propellants (SRP) based on HTPB / AP / Al change their properties with time. Ageing mechanisms are: after-curing, chain rupture by mechanical overload during temperature cycling, oxidative hardening together with loss in strain capability, oxidative chain between particulate fillers (especially AP) and binder matrix [6]. The mechanical properties of composite solid propellants based on HTPB/AP/AL are related to the macromolecular structure of the binder as well as to the content and nature of solid fillers [7]. 
The tensile mechanical properties and damage mechanisms of composite solid propellants are affected under extensive temperatures and strain rates. According to the differences of tensile mechanical properties under different temperatures, and varying strain rates. The quantity of damaged interfaces between particles and binder as well as damage evolvement extents under loading are strain rate dependent. With the rising of loading strain rates, the quantity of the damaged interfaces increases while the development of particle de-wetting damage and the damage accumulation process are postponed [8].

In 2007, a scientific paper was published and presented on an international conference, the paper was explained a technical method for decreasing the curing time of HTPB/AP composite propellants by increasing the curing temperature [9]. Curing time and curing temperature are very important parameters affects the mechanical and performance properties of composite propellants. This chemical process depends on using a certain temperature in a certain duration to solidify the propellant slurry in a certain shape [9]. The curing mechanism depends on the binding systems used. As the time of the curing increase, the curing temperature decrease and vice versa. The paper proved that the curing time can be as short as possible if the suitable temperature is chosen carefully for every period, with consideration of the effect of high temperatures on the propellant properties - especially the burning rate [9]. Some conditions of curing temperatures corresponding to curing times, were suitable to bring the same properties given at the standard conditions [9].

\section{Materials AND Methods}

\section{A. Materials}

The ingredients used in this work consist of (AP) as a main oxidizer, (Al) as a metal fuel, binding system contains (HTPB) as a pre-polymer, Tri(2-methyl-1-aziridinyl) phosphine oxide (MAPO) as a bonding agent, toluene diiscocyanate (TDI) as a cross linking agent and diiso- octyle sebacate (DOS) as a plasticizer), in addition to some additives such as iron acetyl acetonate (FeAA) as a burning rate modifier, Vinyl benzene (VB) as a surface agent and tertiary butyl paracresol (TBP) as an oxidant. The equipment used to achieve the objective of this work consist of mixing equipment (such as AP crusher, material balances, heating ovens and slurry mixer), casting system, curing rooms, laboratory equipment (such as Particle size analyzer, mechanical tester, viscosity meter and density measuring device), in addition to the ground static tester for measuring the propellant performance properties.

\section{B. Methods}

The manufacturing and testing processes of composite propellants were applied in lab scale, using the above equipment and processing systems. The propellant ingredients were mixed with each other carefully and then casted. By the end of the casting process, the samples for ground static and laboratory tests were solidified inside the curing room. For our case study the curing process was taken place at $55^{\circ} \mathrm{C}$ for 6 days as a standard condition. To study the behavior of the propellant in different curing conditions, many experiments

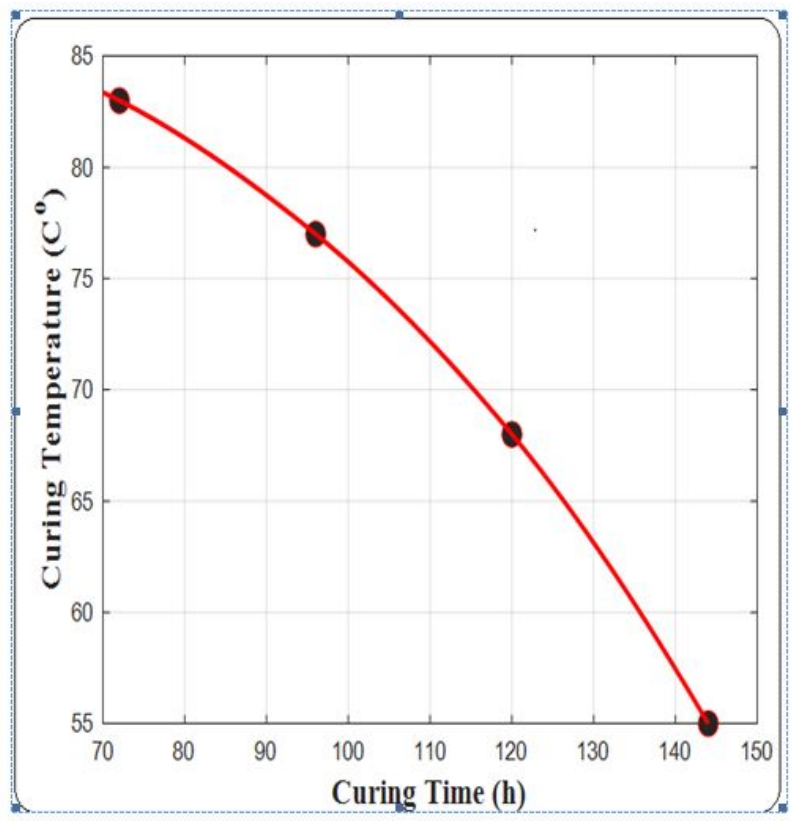

Fig. 1. The relationship between curing time and curing temp.

were carried out for different curing durations $(5,4$ and 3 days) on certain temperature for each period $\left(68^{\circ} \mathrm{C}, 77^{\circ} \mathrm{C}\right.$ and $83^{\circ} \mathrm{C}$ ) respectively. Note that, those times and temperatures were selected according to the long experience for the authors in the propellant manufacturing field and were taken from many different experiments done in the production line. Finally, the samples were tested in the laboratory equipment and the ground static testing device. On the other hand, a selected sample of employees from different sections in the manufacturing, maintenance and marketing departments of composite propellant was taken and questioned. The purpose of the questionnaire is to measure the opinion in the effect of minimizing the curing time on many parameters such as the production processes, the maintenance processes and the period of product delivery for the customer.

\section{RESUltS AND ANALYSIS}

\section{A. Results}

The performance and mechanical properties result for the standard condition $(55 \mathrm{oC}$ in 6 days curing) were carried out. Also, the performance and mechanical properties results for the new conditions for 5,4 and 3 days curing on $68^{\circ} \mathrm{C}, 77^{\circ} \mathrm{C}$ and $83^{\circ} \mathrm{C}$ curing temperatures respectively, were carried out. TABLE I shows the results of standard range and those given for 5,4 and 3 days curing respectively.

Note: The standard condition means those conditions given from the original manufacturing processes. Form the results above, figure 1 was designed and drown to show the relation of every curing time with every curing temperature.

For the results of the questionnaire, $80 \%$ from the selected sample have seen that, the productivity of the propellant can be increased by $100 \%$, the decreasing of the curing time to 3 days can minimize the cost of the curing process by $50 \%$ of the previous cost, the manpower needed for the process 
TABLE I

PARAMETERS RESULTS FOR DIFFERENT CONDITIONS OF CURING TIME AND TEMPERATURE

\begin{tabular}{llllll}
\hline No & Parameter & 6 days $55^{\circ} \mathrm{C}$ & 5 days $68^{\circ} \mathrm{C}$ & 4 days $77^{\circ} \mathrm{C}$ & 3 days $83^{\circ} \mathrm{C}$ \\
\hline 1 & Burning time [s] & 0.70 .9 & 0.884 & 0.843 & 0.841 \\
2 & Average pressure [MPa] & 67 & 6.341 & 5.49 & 6.562 \\
3 & Characteristic velocity[m/s] & $1500-1700$ & 1527.2 & 1555.6 & 1544.1 \\
4 & Burning rate [mm/s] & 1719 & 17.32 & 18.00 & 18.03 \\
5 & Average thrust [FN] & 45 & 4.026 & 4.112 & 4.195 \\
6 & Specific impulse [s] & 230245 & 231.3 & 232.78 & 235.25 \\
7 & Thrust coefficient & 1.41 .6 & 1.51 & 1.50 & 1.52 \\
8 & Tensile strength [MPa] & 0.71 .2 & 0.73 & 0.70 & 0.69 \\
9 & Elongation [\%] & 3350 & 45.07 & 45.46 & 44.60 \\
10 & Density [gm- cm3] & 1.751 .77 & 1.762 & 1.770 & 1.768 \\
\hline
\end{tabular}

TABLE II

QUESTIONNAIRE FOR THE PRODUCER

\begin{tabular}{llll}
\hline No & Questionnaire item & 1 & 2 \\
\hline 1 & The effect of decreasing of the curing time to 3 days on \\
the cost of the curing process & \\
2 & $\begin{array}{c}\text { The percentage of the minimizing the curing process cost } \\
\text { in case of applying the program of } 3 \text { days curing } \\
\text { The effect of decreasing of the curing time to } 3 \text { days on } \\
\text { the loss of the short life raw materials? }\end{array}$ \\
& $\begin{array}{l}\text { The effect of amending of the curing time the } 3 \text { days on } \\
\text { the following and observation process }\end{array}$ \\
\hline
\end{tabular}

TABLE III

QUESTIONNAIRE FOR THE MAINTENANCE TEAM

\begin{tabular}{|c|c|c|c|c|c|c|}
\hline No & Questionnaire item & 1 & 2 & 3 & 4 & 5 \\
\hline 1 & $\begin{array}{l}\text { The effect of decreasing of the curing time to } 3 \text { days on the } \\
\text { depreciation of curing machines and equipment }\end{array}$ & & & & & \\
\hline 2 & $\begin{array}{l}\text { The percentage of the minimizing the depreciation of curing } \\
\text { machines and equipment in case of applying the program of } 3 \text { days curing }\end{array}$ & & & & & \\
\hline 3 & $\begin{array}{c}\text { The effect of decreasing of the curing time to } 3 \text { days on the } \\
\text { depreciation of the electrical energy? }\end{array}$ & & & & & \\
\hline 4 & $\begin{array}{l}\text { The percentage of the minimizing the depreciation of } \\
\text { electrical energy in case of applying the program of } 3 \text { days curing }\end{array}$ & & & & & \\
\hline
\end{tabular}

TABLE IV

QUESTIONNAIRE FOR THE CUSTOMER

\begin{tabular}{|c|c|c|c|c|c|c|}
\hline No & Questionnaire item & 1 & 2 & 3 & 4 & 5 \\
\hline 1 & $\begin{array}{l}\text { If effect of decreasing of the delivery of the } \\
\text { product to the customer from } 10 \text { to } 7 \text { days. }\end{array}$ & & & & & \\
\hline 2 & $\begin{array}{c}\text { The expected percentage for the acceleration of the delivery } \\
\text { time on the defense strategy }\end{array}$ & & & & & \\
\hline 3 & $\begin{array}{c}\text { Do you recommend by changing the delivery time } \\
\text { from } 10 \text { to } 7 \text { days? }\end{array}$ & & & & & \\
\hline
\end{tabular}

of waiting and recording the readings can be decreased by $50 \%$, the customer delivery process was fasted by $30 \%$ of the previous delivery time, the saving of the validity of shortlife materials can be achieved by more than $90 \%$, and the maintenance processes due to equipment depreciation can be improved by $50 \%$ from the previous. The questions designed for this questionnaire and their brief answers were mentioned in tables 2,3 , and 4 below. The numbers from 1 to 5 in the top of columns in tables 2,3 and 4 sign to the percentage of the positive effect of minimizing the curing time to half of the previous period and the delivery time to $70 \%$ from the previous period, the sign indicates to (week, accepted, good, very good and excellent) effect respectively.

\section{ANALYSIS}

The experiments done for different curing times on different temperatures proved that the performance and mechanical properties were not affected by the change of those parameters 
till 3 days and $830 \mathrm{OC}$ respectively. Although some of the properties affected a little, but they were still within the standard range. Moreover, Fig. 1 explain that, the suitable temperature for curing can be chosen for every curing time between 72 and 144 hours according to the producer requirements. Most of the sample members recommended by amending the program of the curing process in the production line of composite propellants gradually, first by applying the program of 5 days curing and then transfer to the program of 4 days curing and finally applying the program of 3 days curing. This amending shall affect many parameters well, such as the cost of the curing process, manpower needed to the curing process, the delivery of the product to the customer, the validity of short-life materials and the maintenance processes due to the machines and equipment depreciation.

\section{CONCLUSION AND RECOMMENDATIONS}

\section{A. Conclusion}

The effect of curing time and curing temperature on the performance and mechanical properties of HTPB-AP composite propellants was carefully studied in this paper, three curing times were selected corresponding to three curing temperatures to achieve the objective of the paper. Moreover, a questionnaire for many sections of the work was surveyed to determine their opinion in the effect of decreasing of the curing time on many processing parameters. The following important points can be concluded:

1) The program of decreasing the curing time of the composite propellants can be applied safely and successfully if the suitable temperature selected carefully and attentively. In this work the curing time for 3 days and the curing temperature of $83^{\circ} \mathrm{C}$ were the suitable conditions.

2) The amending of the curing time from 6 days to 3 days is too useful for the manufacturing processes of composite propellants from many points of view.

\section{B. Recommendations}

By the end of this work, the following recommendations can be mentioned:

1) It is very important to take an interested decision by transferring to the step of minimizing the curing time in the production line to the suitable period after delaying of many years.

2) The validity of the above work must be checked by short materials have good validity and not semi expired.

3) The change of the values of the mechanical properties after curing, must be considered and observed, during the shelf life of the final product.

\section{REFERENCES}

[1] Hui Ma, et al, " catalyzed HTPB/HDI Trimer Curing Reactions and Influence on Pot Life" www.mdpi.com/Journal/Coationgs, 2020

[2] Monique S. McClain, et al "Development and Characterization of a Photo polymeric Binder for Additively Manufactured Composite Solid Propellant Using Vibration Assisted Printing" propellants, explosives, pyrotechnics Journal, First published: March 2020
[3] Eva Landsem, et al, "Isocyanate-Free and Dual Curing of Smokeless Composite Rocket Propellants" Propellants, Explosives, Pyrotechnics Journal, First published November 2012

[4] CH Devi Vara et al, "Effect of the Formulation of Ingredients and the Process Parameters on the Fracture Toughness of HTPB Based Composite Solid Propellant" Journal of Energy and Chemical Engineering, Aug. 2014, Vol. 2

[5] Nikola Gligorijevi, et al "Mechanical Properties of HTPB Composite Propellants in the Initial Period of Service Life" Scientific Technical Review, 2014, Vol.64, No.4, pp.

[6] L. Galfetti "Ageing behaviour of composite rocket propellant formulations inves- tigated by DMA, SGA and GPC" Materials Science 2010

[7] S. Brzi, et al "Viscoelastic properties of hydroxyl-terminated poly(butadiene) based composite rocket propellants" Chemistry, Hemijska Industrija 2014

[8] Liang Zhang, Shijun Zhi, Zhibin Shen "Research on Tensile Mechanical Properties and Damage Mechanism of Composite Solid Propellants Propellants, Explosives, Pyrotechnics Journal 2018

[9] Nagmeldin M. Elamin and M.H.M Abuuznien "Effect of the decreasing of curing time on the performance and mechanical properties of HTPBAP composite propellants". ASAT-12, military colledge [Cairo - Egypt], 2007. 